\title{
Electrochemical Behavior of Gallium-Doped Lithium Titanate in a Wide Range of Potentials
}

\author{
Tatiana Kulova ${ }^{1, *}$, Anna Kuz'mina ${ }^{1}$, Alexander Skundin ${ }^{1}$, Irina Stenina $^{2}$, Andrei Yaroslavtsev ${ }^{2}$ \\ ${ }^{1}$ Frumkin Institute of Physical Chemistry and Electrochemistry of the Russian Academy of Sciences, \\ 31-4 Leninskii prospect, Moscow, 119071, Russia \\ ${ }^{2}$ Kurnakov Institute of General and Inorganic Chemistry of the Russian Academy of Sciences, 31 \\ Leninskii prospect, Moscow, 119991, Russia \\ *E-mail: thulova@mail.ru
}

doi: $10.20964 / 2017.04 .04$

Received: 29 December 2016 / Accepted: 20 January 2017 / Published: 12 March 2017

\begin{abstract}
A synthesis method of gallium-doped lithium titanate is proposed. The effect of gallium-doping on electrochemical properties of the $\mathrm{Li}_{4+\mathrm{x}-3 \mathrm{y}} \mathrm{Ti}_{5-\mathrm{x}} \mathrm{Ga}_{\mathrm{x}+\mathrm{y}} \mathrm{O}_{12}(\mathrm{x}+\mathrm{y}=0.2 ; \mathrm{y} / \mathrm{x}=2.56)$ is studied in detail. It has been established that the cycling range extension leads to a reversible insertion of more than four lithium ions per formula unit of gallium-doped lithium titanate, which corresponds to a reversible capacity of about $280 \mathrm{mAh} \mathrm{g}^{-1}$. Gallium doping results in the increased cycling stability of lithium titanate in a wide range of potentials. The good electrochemical performance of the gallium-doped lithium titanate can be attributed to the increase in conductivity and effective diffusion coefficient.
\end{abstract}

Keywords: Gallium doping, lithium titanate, wide potential range, lithium-ion battery

\section{FULL TEXT}

(C) 2017 The Authors. Published by ESG (www.electrochemsci.org). This article is an open access article distributed under the terms and conditions of the Creative Commons Attribution license (http://creativecommons.org/licenses/by/4.0/). 